\title{
Parasites of two co-occurring house gecko species, Hemidactylus frenatus and Gehyra mutilata from Central Sri Lanka
}

\author{
P.D. Mahagedara and R.S. Rajakaruna* \\ Department of Zoology, Faculty of Science, University of Peradeniya, Peradeniya.
}

Received: 06 March 2012 In Final Form: 30 May 2013

\begin{abstract}
Two house gecko species, the Asian house gecko, Hemidactylus frenatus (Schlegel, 1836) and the four-clawed gecko, Gehyra mutilate (Wiegmann, 1834) inhabiting urban areas in Kandy and Kegalle districts were examined to determine the types of ecto and endo parasites, their prevalence and intensity of infections. A total of 45 geckos from the two species were dissected after anesthetizing of which 21 individuals (47\%) were infected with one or more parasites. Both host species were infected by helminthes such as the nematodes and a fluke species. In addition mites (Geckobia sp.) and an acanthocephalan (Acanthocephalus serendibensis), and ciliates were found only in $\mathrm{H}$. frenatus. Although the two gecko species co-occur, some parasites show host specificity. Nematode infections (possibly Oxyuris infection) were the most common type with $29 \%$ prevalence. Although A. serendibensis has been previously described from an agamid, Ceratophora stoddarti, and two geckonids Cnemaspis kandiana and Cnemaspis tropidogaster from Sri Lanka, $\mathrm{H}$. frenatus presents a new host record for $A$. serendibensis and occurred at high intensity of 510 worms per host. There were no parasites in the blood or body cavity of the geckos examined. More female geckos were infected with parasites than males $(x 2=5.20, p<0.05)$. Although H. frenatus harboured parasites of all five groups while G. mutilate had only two groups, there was no significant difference in the prevalence of infections between the two species $(x 2=1.16, p>0.05)$. None of the identified parasite species have a zoonotic potential.
\end{abstract}

Key words: House geckos, parasites, Hemidactylusfrenatus, Gehyra mutilate

Introduction

Twenty species of geckos (Family: Gekkonidae) have been recorded in Sri Lanka (de Silva, 2001) and those found in human dwellings are called "house geckos". In this study we aim to identify the parasites found in two house gecko species, the Asian house gecko, Hemidactylus frenatus and the four-

\footnotetext{
"Department of Zoology, Faculty of Science, University of Peradeniya, Peradeniya.
} 
Parasites of two co-occurring house gecko species.......

clawed gecko, Gehyra mutilate and to determine prevalence and intensity of infections. Hemidactylus frenatushas a worldwide subtropical-tropical distribution and a patchy occurrence outside Asia (Goldberg et al., 1998). International movement of ships and cargo has assisted its spread across the world and populations now exist in numerous islands and countries (Csurhes and Markula, 2009). There is some evidence that $H$. frenatus can compete and perhaps replace locally native gecko species, especially in urban areas. It is very adaptable and prey on insects and spiders. Gehyra mutilata ranging from India to Myanmar, Indo-China, the Malay Peninsula, and Indonesia to Oceania and coastal Mexico (Goldberg et al., 1998). It is also very adaptable to its surrounding and usually prefers woodlands, rocky areas and human habitats.

Parasitism remains a neglected aspect of Sri Lankan reptile biology hence little is known about the parasites that infect geckos. The first report dates back to 1906 where von Linstow described a nematode, Oxyuris megaloon (currently Parapharyngodon species) from Hemidactyulus leschenaultii. As part of a broader survey of the parasites of endemic element of Sri Lankan vertebrates, Cruz and Ching (1975) carried out helminths surveys of three gecko species; Hemidactylus brookii, $H$. triedruslankae and C. kandianus. They reported an acanthocephalan Acanthocephalus serendibensis in Cnemaspis kandiana and later Crusz (1984) found a digenean, Paradistomum $\mathrm{sp}$. in Hemidactylus parvimaculatus. Subsequently, two more studies have been carried out; one on the golden gecko, Calodactylodes illingworthorum inhabiting Nilgala fire savanna in Monaragala district (de Silva et al., 2004) and another on geckos of Knuckles massif (de Silva et al., 2005). A more recent survey of nine gecko species recorded many helminthes (Goldberg et al., 2011).

\section{Materials \& Methods}

Geckos inhabiting houses from selected urban sites in Kandy and Kegalle districts in Central Sri Lanka were collected from August 2007 to February 2008. Geckos were identified, euthanized within $12 \mathrm{hr}$ of capture, and necropsies were carried out. Information about sex, microhabitat and the physiological condition of each animal was recorded. External areas of the body such as head region, armpits and anal area and between fingers and toes were examined for ectoparasites. Parasites found were transferred into $70 \%$ ethanol and were observed under the dissection microscope and identified. 
The body cavity was opened by a longitudinal incision, and the gastrointestinal tract was removed and opened. The esophagus, stomach, small were identified after glycerol wet mounts. Smears were prepared from the gut content and were fixed in Shouding's fixative and then double stained in Harris'

Table 1 Site of infection, prevalence and intensity of parasites recorded from G. mutilata and H. frenatus

\begin{tabular}{|l|l|l|l|l|l|}
\hline \multirow{2}{*}{$\begin{array}{l}\text { Type of } \\
\text { Parasite }\end{array}$} & $\begin{array}{l}\text { Site of } \\
\text { infection }\end{array}$ & \multicolumn{2}{|c|}{ Prevalence (\%) } & \multicolumn{2}{c|}{ Mean intensity (Range) } \\
\cline { 3 - 6 } & $\begin{array}{l}\text { Skin, } \\
\text { underarm, } \\
\text { between } \\
\text { toes }\end{array}$ & - & $4 / 21(19 \%)$ & - & $5(2-7)$ \\
\hline Nematiate & $\begin{array}{l}\text { Small } \\
\text { intestine }\end{array}$ & $10 / 24(42 \%)$ & $6 / 21(29 \%)$ & $4(1-8)$ & $3(1-3)$ \\
\hline Flukes & $\begin{array}{l}\text { Stomach \& } \\
\text { Small } \\
\text { intestine }\end{array}$ & $3 / 24(13 \%)$ & $1 / 21(5 \%)$ & $2(1-4)$ & 1 \\
\hline $\begin{array}{l}\text { A. } \\
\text { serendibensis }\end{array}$ & $\begin{array}{l}\text { Small } \\
\text { intestine }\end{array}$ & - & $2 / 21(10 \%)$ & - & $7(5-10)$ \\
\hline Ciliates & Stomach & - & $1 / 21(5 \%)$ & - & 20 \\
\hline
\end{tabular}

intestine, and large intestine were examined for parasites under a dissecting microscope. Identification was made from these temporary wet mounts. A portion of each part of the gut of each individual was placed on a watch glass and a few drops of saline were added on to it and observed under the light microscope. Live parasites were separated by using a dropper and preserved in $70 \%$ ethanol. Permanent slides were prepared by using the single staining procedure (Borax Carmine) for identification. Nematodes
Heamatoxyline and Eosine and observed under the light microscope for parasites and eggs. The heart was removed and a few drops of blood were taken from a puncture. Blood smears were prepared on a microscope slide and stained with Leishman's dye and observed for blood parasites. The prevalence and the mean intensity of different types of parasites were determined. The difference of prevalence in overall infection was compared between males and females, two sites and two species using a chi 
square test. Handling of live geckos and euthanizing were carried out according to protocols approved by the Canadian Council on Animal Care (CCAC, 1992).

\section{Results}

All the geckos dissected looked healthy and active. External appearances of any of the species did not indicate symptoms of any disease. Their microhabitats were mostly inside houses on walls, roofs and other surfaces where there were lights to attract insects. They were also found in outdoors like under logs and surface of the tree barks in the vicinity of the house. Of the 45 individuals examined, 21 (47\%) were infected with one or more parasites. The parasitic fauna found in the two species consisted of five broad groups namely one ectoparasitic mite and endo parasites such as nematodes, flukes, acanthocephalans and ciliates (Table 1). There were no parasites in the blood or body cavity of the geckos examined.

Mites were found only in $H$. frenatus collected from both sites with an overall prevalence $19 \%(4 / 21)$ and an average intensity of five (Table 1). Their body was usually flattened, bright orange to red in color, eyes seemingly absent, four pairs of legs were present except in larvae and body is circular to broadly oval in outline and densely hairy. They were found attached to the skin of hind and forelegs in between fingers and under side of the arms.

Table 2 Overall prevalence and intensity of infections in G. mutilata and H. frenatus from the two study sites in Kegalle and Kandy

\begin{tabular}{|l|l|l|l|}
\hline \multirow{2}{*}{} & \multicolumn{2}{|c|}{ Prevalence (\%) } & \multirow{2}{*}{$\chi^{2}$} \\
\cline { 2 - 3 } & G. mutilate (24) & H. frenatus (21) & \\
\hline Kegalle (22) & $8 / 12(67 \%)$ & $3 / 10(30 \%)$ & \multirow{2}{*}{$0.55(p>0.05)$} \\
\hline Kandy (23) & $5 / 12(42 \%)$ & $5 / 11(45 \%)$ & \\
\hline Total & $13 / 24(54 \%)$ & $8 / 21(38 \%)$ & $1.16(p>0.05)$ \\
\hline Male (14) & $2 / 7(29 \%)$ & $1 / 7(14 \%)$ & \multirow{2}{*}{$5.20(p<0.05)^{*}$} \\
\hline Female (31) & $10 / 17(59 \%)$ & $8 / 14(57 \%)$ & \\
\hline
\end{tabular}


Of the endoparasites, nematode infection (possibly Oxyuris infection) was the most common type with a high prevalence of $42 \%$ in G. mutilata and $29 \%$ in H. frenatus. All the nematodes were found in the small intestine. One species of digenetic trematode was found in the stomach and small intestine of both species which could be Mesocoelium monas. DNA studies are required to confirm the morphological identification of the nematode and trematode species. Larval stage of Acanthocephalus serendibensis and ciliates were found only found in $\mathrm{H}$. frenatus collected from Kandy district. None of the gut associated organs had any parasites. There were no parasites in blood smears or in the body cavity of dissected specimens of both gecko species.

There was no difference in the prevalence of infection between the two sites Kandy and Kegalle (Chi Square test, $p>0.05$; Table 2) or between the two species $\left(\chi^{2}=1.16, p>0.05\right)$. However, $H$. frenatus harboured parasites of all five groups while $G$. mutilate had only nematodes and flukes (Table 2). More female geckos were infected with parasites than males (Chi Square test, $p<0.05$; Table 2).

\section{DISCUSSION}

This study revealed the presence of five different parasitic groups including nematodes, flukes, acanthocephalans, ciliates and mites belonging to various taxa in the two gecko species $G$. mutilate and $H$. frenatus collected from selected sites in Kandy district and Kegalle district. Of these parasites, the mite Geckobia, ciliates and $A$. serendibensis was recorded only from $H$. frenatus. Of the two hosts, $H$. frenatus harboured more diverse parasitic species than G. mutilata and is thus reflective of the host's ability to sustain various parasitic requirements. Although the two gecko species shared the same habitat some parasites show host specificity where $G$. mutilate was infected with only helminthes while $H$. frenatus had acanthocephalans, ciliates and mites in addition to the helminthes.

Geckobia belongs to Family Pterygosomatidae, which are usually confined to lizards and all their developmental stages are ectoparasitic (Simpson and Sarda, 1985). Geckos observed in the Knuckles massif such as Cyrtodactylus soba, Cnemaspis kandianus were found infested with red mites (de Silva, 2005). Mite infections can cause problems with sloughing old skin and are associated with significant shorter life spans, at least for geckos found indoors (Walter and Shaw, 2002). The mite species Geckobia tasmani has been recorded from $\mathrm{H}$. mabouia from Tanzania (Simpson and Sarda, 1985) and $G$. 
bataviensis from $H$. frenatus from Australia (Walter and Shaw, 2002).

In a recent study carried out in Sri Lanka recorded two nematode species Skrjabinelazia hemidactyli from $G$. mutilate and Spauligodon hemidactlylus from $H$. frenatus (Goldberg et al., 2011) and earlier Oxyurismegaloon from Hemidactyulus leschenaultia (von Linstow, 1906). Although the nematodes isolated in the present study morphologically resembled Oxyuris sp., further studies are needed for confirmation.

Acanthocephalus serendibensis was originally described from agamid, Ceratophora stoddarti (Cruz and Mills 1970) and then later in geckonid Cnemaspis kandiana (Cruz and Ching, 1975) and recently in Cnemaspis tropidogaster (Golberet al., 2011). Hemidactylus frenatus presents a new host record for $A$. serendibensis.

These two gecko species were infected by generalist helminth species such as the nematodes and the fluke species but Acanthocephala, ciliates and mites were only found in $H$. frenatus. Geckos are easily spread across the world through ships and cargo and the parasites that they harbor also move with the host species.

\section{Acknowledgements}

Authors thank Y.G. Ariyaratne and Varunilmbuldeniya for their technical assistance.

\section{References}

1. Canadian Council on Animal Care. Guide to the Care and Use of Experimental Animals. Vol 1 and 2. Ottawa, ON, Canada (1992).

2. H. Crusz, Parasites of endemic and relict vertebrates: a biogeographical review. Pages 321-351 in C. $\mathrm{H}$. Fernando, ed. Ecology and Biogeography in Sri Lanka. Dr. W. Junk Publishers, The Hague, Netherlands (1984).

3. H. Crusz, and C.C. Ching, Parasites of the relict fauna of Ceylon. VI. More new helminths from amphibians and reptiles, a new host-record and redescription of Acanthocephalus serendibensis Crusz and Mills 1970. Ann. Parasitol. Hum. Comp.50:531538 (1979).

4. H. Crusz and E. V. Mills, Parasites of the relict fauna of Ceylon. I. Acanthocephalus serendibensis $\mathrm{sp}$. nov.from the Ceylon horn-nosed 
lizard, Ceratophora stoddarti Gray. Ann. Parasitol. Hum. Comp.45:13-19 (1970).

5. H. Crusz and M. A. K. Daundasekera, Ann. Parasitol. Hum. Comp.63, 439447 (1988).

6. H. Crusz and V. Sanmugasunderam, Ann. Parasitol. Hum. Comp.46, 575588 (1971).

7. de Silva, 2001) S. csurhes and A. markula Asian House Gecko (Hemidactylus frenatus) in Australia. In Pest Animal risk management. Queensland, Australia (2009).

8. de Silva, R. P. V. J. Rajapakse, A. M. Bauer, W. M. J. De Silva, C. C. Austin, S. Goonewardene, Z. Hawke, V. Vanneck, A. Drion, and M. M.
Goonasekera. Lyriocephalus (Special Issue) 5, 199-205 (2004).

9. de Silva, R.P.V.J. Rajapaksa, R.R.M.K.K. Wijesundera, A. Bauer, S. Goonewardene, J. Drake, C.C. Austin and N.A.N.D. Perera, Lyriocephalus Special Issue. 6 (1-2), 173-177 (2005).

10. S.R. Goldberg, C. R. Bursey, A.M. Bauer, A. De Silva and C.C. Austin, Comp. Parasitol. 78(2), 359-366 (2011).

11. S.R. Goldberg, C.R. Bursey and H. Cheam J. Parasitol. 84(6), 1295-1298 (1998).

12. P.E. Simonsen and R.K. Sarda, J. Herpetol. 19(3), 428-430 (1985).

13. D.E. Walter, D.E. and M. Shaw, Aus. J. Entomol. 41, 30-34 (2003) 